\title{
O HISTORIADOR E A CARTOMANTE Diálogo de identidades discursivas em $A$ hora da estrela ${ }^{(*)}$
}

\section{Roberto Sarmento Lima ${ }^{(*)}$}

Resumo: $\mathrm{Na}$ instância narradora de A hora da estrela, Clarice Lispector combina dois pontos de vista que se cruzam e se auto-repelem: a visão do historiador factual, Rodrigo S. M., narrador oficial capaz de promover o discurso sério, verossímil, ligado à tradição das narrativas, e o discurso inverso, encenado literariamente pela cartomante, que, mesmo sendo figura da diegese, e não da enunciação, se imiscui metaforicamente no ato de narrar, pelo qual são postos em xeque a concepção beletrista da literatura e o conceito verista de ilusão da realidade que as narrativas, de um modo geral, já alçaram a critério de representação literária.

Palavras-chave: Discurso; história; paródia; modernidade

Numa carta a Olga Borelli, Clarice Lispector declarou, num misto de confissão pessoal e declaração literária, que trabalhava intensamente sobre seus textos (referia-se na ocasião a Água viva). escrevendo-os e reescrevendo-os sempre, de modo que, a cada retorno aos escritos, ia fazendo modificações, acrescentando, retirando... A escrita, para ela, enquanto processo, era um movimento contínuo, manifestando-se ora na inserção de fragmentos, ora no apagamento de passagens já compostas, dando a impressão de que mais de um texto circulava em torno do texto central.

No que toca diretamente à novela $A$ hora da estrela, Clarice elabora - na sua espécie de prefácio, que ela chamou de "Dedicatória do Autor (Na verdade Clarice Lispector)" - uma verdadeira cartatestamento de seu trabalho literário, a qual, apesar do tom confessional, pode ser considerada uma pequena peça de ficção, à

(") Trabalho apresentado no VII Congresso da Associação Brasileira de Literatura Comparada (Abralic) - "Terras e Gentes". em Salvador. Bahia. em 2000.

(*) Professor Doutor da área de Literatura Brasileira, do Programa de PósGraduação em Letras e Lingüística da Universidade Federal de Alagoas (Ufal). 
margem do texto principal, encontrando-se nela a pista para o entendimento desse livro, de 1977, e talvez de toda a sua obra.

Assim, nessa mesma "dedicatória do autor", que suscita um modo de leitura de A hora da estrela, podemos visualizar a flutuação de motivos que funda a estética de Clarice - oscilação essa que se reflete na dispersão de significados e propósitos textuais, tanto (1) ao problematizar o ato composicional ("O que me atrapalha a vida é escrever"), quanto (2) ao considerar o sujeito enunciador como um sujeito vário, que se multiplica e se divide ("pois não agüento ser apenas mim, preciso dos outros para me manter de pé"). Dessas duals últimas menções à construção do texto, nessa "dedicatória" que abre a escrita-leitura de A hora da estrela e que serve de antecipação, diria teórica, à questão básica do processo textual clariciano -, faço derivar, pelo menos também, duas ações fundamentais que vão conduzır a presente análise.

Antes de tudo, pretendo verificar a posição de quem dirige o desenvolvimento dos fatos narrados, podendo aqui ser percebido como um concurso de comportamentos e atitudes situados entre os limites das óticas do historiador e do literato, vistos respectivamente através do narrador oficial, Rodrigo S. M., e da figura da cartomante; em seguida, iluminar a discussão, no texto, da posição apequenada e caricata desse literato, representado obliquamente pela cartomante. cujo papel, em $A$ hora da estrela, seria o de criar a ilusão de real por ela subverter a ordem dos fatos narrados, já que mente sobre o destino da protagonista, criando uma ficção dentro da fiç̧ão. Esșa duplicidade de orientação discursiva permite, enfim, o questionamento sempre novo acerca da natureza e finalidade da arte, que vai da concepção beletrista - ridicularizada no texto através da cartomante, servindo de contraponto ao narrador oficial - àquela que se impôs nat modernidade, fragmentada e carente de um centro decisório e sólido, marca, aliás, da escrita de Clarice Lispector. Bem a propósito, vale salientar que o ser da narrativa moderna seria, segundo Bakhtin!, o de parodiar justamente a fixidez dos gêneros e a própria linguagem literária - razão que nos leva, aqui, a fazer avultar a função textual (e narratorial) da cartomante, em uma espécie de subtexto ou narrativa dentro da narrativa.

1 BAKHTIN, Mikhail. Questões de literatura e de estética: a teoria do romance. Tradução Aurora Fornoni Bernardini. São Paulo: Hucitec; Fundação para o Desenvolvimento da Unesp. 1988. 
Diálogo de identidades discursivas em $A$ hora da estrela

\section{Rodrigo S. M. não quer ir ao dentista}

A relação que se estabelece, desde o começo, entre a autora (que se autodenomina autor, primeira ficção, portanto) e o texto que compõe é, flagrantemente, de desdém e áspero mal-estar. Diz Clarice ao iniciar a Dedicatória: "Pois que dedico esta coisa aí ao antigo Schumann e sua doce Clara que são hoje ossos, ai de nós". Reproduzindo-se em escala definidamente ficcional, já na pele de Rodrigo S. M., esse sintoma de desprezo do narrador pelo seu ofício se transforma - através de uma visão en abyme (uma vez que a "dedicatória" já contém em si os fundamentos por que se organiza a narrativa de $A$ hora da estrela) - em uma manifestação de perda de orgulho literário, capaz de revelar a incapacidade de perceber onde se situa a raiz do problema que quer desvendar: "Tudo no mundo começou com um sim. Uma molécula disse sim a outra molécula e nasceu a vida. Mas antes da pré-história havia a pré-história da préhistória e havia o nunca e havia o sim. Sempre houve. Não sei o quê, mas sei que o universo jamais começou". 2

Nessa confusão de motivos, misturam-se traços de mundos culturais provenientes da escrita do Gênese, da Biologia e da História, encarados como campos limítrofes do conhecimento e da escrita; Clarice Lispector problematiza, assim, a própria escrita da literatura pela boca de Rodrigo S. M., o narrador que, não obstante as hesitações iniciais, quer remontar a uma história, dando-lhe caráter de discurso sério, legitimando o discurso literário ao ancorá-lo em discursos de prestígio social, como o bíblico, o científico e o histórico. Mas não perde de vista a ponte que estabelece com o ficcional: "Se esta história não existe, passará a existir. Pensar é um ato. Sentir é um fato" (HE, p.11).

O estatuto do narrador é, assim, dividido entre os discursos que se entrecruzam, como se, de longe, ele temesse e anunciasse a perda dos limites. Sob a responsabilidade de Rodrigo S. M. correm então duas narrativas paralelas, que, por vezes, se tangenciam, se interinfluenciam mutuamente: a narrativa do historiador (sula metalinguagem) e a narrativa dos fatos (a própria fábula). Já se notou que a narrativa da história e a da literatura fazem parte de uma classe

As citações do texto de Clarice Lispector para este artigo estão em A hora da estrela. Rio de Janeiro: Rocco, 1998, doravante nomeada HE. A citação aqui foi retirada da página 11. Os grifos são sempre meus. 
mais ampla de histórias: "textos de demonstração narrativa", noção que abrigaria todo tipo de texto narrativo, literário ou não-literário. Em A hora da estrela sobressai a narrativa do historiador-teólogo, representante da visão da história como causalidade e finalidade, que. mesmo contrariando a visão moderna a respeito da dispersão dos discursos, tenta, de todas as maneiras, articular e submeter a si os demais pontos de vista: "Deus é o mundo. A verdade é sempre um contato interior e inexplicável. A minha vida a mais verdadeira é irreconhecível, extremamente interior e não tem uma só palavra que a signifique" (HE, p.11).

Apesar da recorrência à solenidade do discurso sério, como o religioso, reino do inefável e do inatingível, o texto de A hora da estrela quer atingir o social mais banal - falar de uma nordestina que foi morar na cidade grande, no Sudeste do Brasil, a alagoana Macabéa, mais uma anônima que se perde na impiedade das calçadas urbanas e dos edifícios altos, que a tornam ainda menor. Por isso, a conduta do narrador assume o lugar não da escrita preferencialmente ficcional, mas da escrita que toma emprestados os rigores da história factual, comprovando-se que o discurso do historiador luta por ser soberano nessa construção. A consequiencia dessa luta surda entre os limites da história e da literatura, que poderiam constituir fronteiras sutis, é tornar visível (com o também visível primado do discurso do tentativa de definição de marcos diferenciais entre a literatura e a história: "Escrevo neste instante com algum prévio pudor por vos estar invadindo com tal narrativa tão exterior e explícita. [...] Será essa história um dia o meu coágulo? Que sei eu. Se há veracidade nela-e é claro que a história é verdadeira embora inventada - que cada um a reconheça em si mesmo [...]"(HE, p.12).

Esse paradoxo - "a história é verdadeira embora inventada" -, motor formal dessa narrativa, se torna flagrante e é simbolizada em uma dor, uma dor de dentes, que assim metaforiza o conflito da convivência dos discursos do historiador e do artista, qual seja, o de ser fiel à verossimilhança dos fatos ou simplesmente imaginá-los. Dor de dentes, tornada pior porque é uma dor que não quer ser curada,

\footnotetext{
Cl. CULLER, Jonathan. Teoria literária: uma introdução. Tradução) Sandra Vasconcelos. São Paulo: Beca Produções Culturais Lıı... 1999, p. 33.
} 
porque é nela que paradoxalmente se perfaz a narrativa: " $A$ dor de dentes que perpassa esta história deu uma fisgada funda em plena boca nossa. Então eu canto alto agudo uma melodia sincopada e estridente - é a minha própria dor, eu que carrego o mundo e há falta de felicidade" (HE, p.11).

Sintoma da modernidade, a literatura se faz com carências, lacunas e defasagens. A escrita não é um campo de felicidade, mas, como disse Rodrigo S. M., de falta.

A metáfora continua: "Devo acrescentar um algo que importa muito para a apreensão da narrativa: é que esta é acompanhada do princípio ao fim por uma levíssima e constante dor de dentes, coisa de dentina exposta" (HE, p. 24).

A dor de dentes de tal modo simboliza o mundo em agonia, em deterioração, que toda a realidade parece ser uma grande cratera, um buraco, onde todos os seres são igualmente corroídos por uma espécie de cárie. O narrador-historiador se atém aos fatos, a registrálos, parecendo não ter a liberdade do ficcionista de dar outro rumo à narrativa. Por isso, todo o mundo compartilha de sua dor, de sua impotência:

O pior momento de sua vida era nesse dia ao fïm da tarde: caía em meditação inquieta. o vazio do seco domingo. Suspirava. Tinha saudade de quando era pequena - farofa seca - e pensava que fora feliz. [...] Juro que nada posso fazer por ela. Afianço-vos que se eu pudesse melhoraria as coisas. Eu bem sei que dizer que a datilógrafa tem o corpo cariado é um dizer de brutalidade pior que qualquer palavrão (HE, p.35).

A dor do mundo que atinge a todos é incompatível com o prazer, incluindo-se o artístico, 'sublime e supremo'. Só que para a teoria da modernidade não existe esse prazer supremo, ou melhor, se ele existe, é reelaborado em nome de uma estética que não abre mão da consciência e da autoconsciência do texto, de modo que se cruzam, sem espanto, as áreas semânticas do prazer e da dor - novo paradoxo, cuja percepção ocorre numa manifestação de espanto: "Macabéa, esqueci de dizer, tinha uma infelicidade: era sensual. Como é que num corpo cariado como o dela cabia tanta lascívia, sem que ela soubesse que tinha?"(HE, p.61). 
A dor de dentes é a figura a que se submete a construção de $A$ hora da estrela, marcando sua inserção na modernidade - dor essa que provém da consciência da escrita, de não poder dizer de outro modo, dados os frágeis limites que isolam a literatura dos rigores da história, colocados ambos os discursos em situação de complementaridade e simetria. A missão do historiador, de que se investe Rodrigo S. M., é a do empedernido cronista, que, sem querer deixar de ser o literato, não pode afastar-se do fato que presencia e registra, por compromisso assumido desde o início da narrativa: "Estou me interessando terrivelmente por fatos: fatos são pedras duras. Não há como fugir. Fatos são palavras ditas pelo mundo" (HE. p.71).

\section{A cartomante engana}

Já o lugar reservado, em $A$ hora da estrela, para a discussão sobre a função estética do texto se encontra no episódio em que Macabéa procura a cartomante para adivinhar o seu futuro, na esperança de que este fosse venturoso. Diametralmente oposto à figura da cartomante, o narrador Rodrigo S. M. - que quer funcionar como um objetivo historiador dos fatos que relata - rejeita qualquer interferência literária, seja por admitir que não segue levianamente uma linguagem artística (visível em "Relato antigo, este, pois não quero ser modernoso e inventar modismos à guisa de originalidade" ou em "é um relato que desejo frio. Mas tenho o direito de ser dolorosamente frio, e não vós"); seja por assumir-se como um historiador que, como desejou Gustave Lanson, queria expulsar de si toda a subjetividade para que, à semelhança das ciências naturais que Ihe serviram de modelo, só sobrasse a objetividade do discurso.
minimizando-se o papel da invenção, já que sua história nada tem de
grandioso ("O que escrevo é mais do que grandioso ("O que escrevo é mais do que invenção, é minha obrigação contar sobre essa moça entre milhares delas. E dever meu, nem que seja de pouca arte, o de revelar-lhe a vida"); seja, finalmente, por execrar a visão beletrista que um dia unificou as escritas da história e da literatura, até pelo menos o século XVIII, ${ }^{+}$cisão que a
alta modernidade patrocinou:

Cf. essa discussão em LIMA, Luiz Costa. Terra ignota: a construção de Os sertôes. Rio de Janeiro: Civilização Brasileira, 1997. História c literatura, p. 213-237. 
É claro que, como todo escritor, tenho a tentação de usar termos suculentos: conheço adjetivos esplendorosos, carmudos substantivos e verbos tão esguios que atravessam agudos o ar em vias de ação [...] Mas não vou enfeitar a palavra pois se eu tocar no pão da moça esse pão se tornará em ouro - e a jovem (ela tem dezenove anos) e a jovem não poderia mordê-lo. morrendo de fome. Tenho então que falar simples para captar a sua delicada e vaga existência. Limito-me a humildemente - mas sem fazer estardalhaço de minha humildade que já não seria humilde - limito-me a contar as fracas aventuras de uma moça na cidade toda feita contra ela. Ela que deveria ter ficado no sertão de Alagoas com vestido de chita e sem nenhuma datilografia [...] (HE, p.15).

Já a cartomante, muito ao contrário de Rodrigo S. M., é símbolo da fartura, da gordura, da adiposidade, que representam no texto o estilo literário em sua versão beletrista. "Quem", como Rodrigo S. M. (aproveitando aqui uma distinção fornecida por Ernst Robert Curtius), "precisava dominar um assunto tão extenso não podia servir-se desse meio, tendo de escolher o sermo simplex, aproximado da fala cotidiana". 5 código tinha de ser - no caso do relato rigoroso dos fatos - simples. Diz ainda Curtius referindo-se à prosa medieval: "Um historiador não podia proceder de outro modo" (p.202). "A prosa "simples' (sermo simplex) permanece naturalmente como o veículo normal para cartas, crônicas, histórias, ciência e hagiografia" (p.204). Em oposição, o sermo artifex seria a linguagem artística, artificial e artificiosa. Na minha abordagem, entretanto, o estilo simples se atém à necessidade de o narrador-historiador manter a posição de possivel distanciamento em relação à matéria narrada, já que as considerações sobre a construção da narração, entendida como o discurso historiográfico linear, correm paralelamente - embora às vezes se misturem - aos acontecimentos narrados. Veremos mais adiante como se desconstrói esse discurso pretensamente objetivo e linear.

Enquanto Rodrigo S. M. insiste na simplicidade do relato,

CURTIUS, Emst Robert. Literamara enropéia e Idade Média latina. Tradução Teodoro Cabral e Paulo Rónai. São Paulo: Hucitec; Edusp. 1996 (Clássicos, 2), p. 202. 
Voltando a mim: o que escreverei não pode ser absorvido por mentes que muito exijam e ávidas de requinte. Pois o que estarei dizendo será apenas nu [...]. Que não se esperem, então, estrelas no que se segue: nada cintilará, trata-se de matéria opaca e por sua própria natureza desprezível por todos. É que a esta história falta melodia cantabile. O seu ritmo é às vezes descompassado. E tem fatos. Apaixonei-me subitamente por fatos sem literatura - fatos são pedras duras e agir está me interessando mais do que pensar, de fatos não há como fugir (HE, p. 16).

Tudo isso, sim, a história é história. $[\ldots] \mathrm{E}$ a palavra não pode ser enfeitada e artisticamente $v \tilde{a}$, tem que ser apenas ela (HE, p.20).

por sua vez, a linguagem da cartomante é estilisticamente artificial. em que o uso abusivo de diminutivos contribui para o adocicamento do dizer:

- O meu guia já tinha me avisado que você vinha me ver, minha queridinha. Como é mesmo o seu nome? Ah. é? É muito lindo. Entre, meu benzinho. Tenho uma cliente na salinha dos fundos, você espera aqui. Aceita um cafezinho, minha florzinha?

O narrador acompanha esse movimento linguiístico, parafraseando a linguagem da cartomante (isso significa que, ao servir-se da paráfrase, está tentando ser fiel aos fatos, ideologicamente preso a um centro regulador, que vem de fora para dentro do texto): "[...] madama Carlota era enxundiosa, pintava a boquinha rechonchuda com vermelho vivo e punha nas faces oleosas duas rodelas de ruge brilhoso" (HE, p.72).

Com a cartomante opera-se justamente o oposto do que acontece com o historiador. Ela nega peremptoriamente, numa espécie de denegação, a carga de ficção de que é investida: "Pois faz bem porque eu não minto" (p. 73). No entanto, a sua imagem, o lugar em que vive, sua fala, tudo a descredencia como ser da verdade ao tempo $\mathrm{em}$ que revela seu poder de criar ficções. Tudo nela, e no ambiente que a cerca, é falso: "Lá tudo era de luxo. Matéria plástica amarela nas poltronas e sofás. E até flores de plástico" (p. 72). Ela mesma "parecia um bonecão de louça meio quebrado": "grande dama cujo 
ruge brilhante dava-lhe à pele uma lisura de matéria plástica" (p. 76). A cartomante, assim, representa simbolicamente a paródia de si mesma ao ridicularizar as cartomantes em geral, pela exposição cômica do seu estereótipo; e, sobretudo, constitui a paródia do próprio discurso literário, entendendo-se, como quer Bakhtin (1988, p.399), que o romance é um gênero que, estruturalmente, se afina com o mundo contemporâneo no momento em que promove uma profunda autocrítica de sua própria linguagem - é isso que acontece através do contraste entre o discurso do narrador Rodrigo S. M. e o da cartomante - e, também, uma crítica da linguagem artística: a cartomante, enfim, põe em xeque a validade do "princípio de literaturidade" (de novo, Bakhtin) que caracteriza o discurso literário tradicional, com o desmascaramento do seu artificialismo.

E, nesse contexto, ressurge a metáfora da faculdade de narrar, ligada à área da boca e dos dentes. Não se trata, porém, da dor de dentes de Rodrigo S. M., porque este estava comprometido com a verdade dos fatos que eram como "pedras" (por isso a dor o incomodava); agora trata-se da metáfora dos dentes falsos, a qual traduz a hipócrita harmonia do "princípio de literaturidade":

- [...] Por falar em morder, você não pode imaginar que dentes lindos eu tinha, todos branquinhos e brilhantes. Mas se estragaram tanto que hoje uso dentadura postiça. Você acha que se nota que são postiços?

— Não senhora (HE, p.74).

Tão postiça, como os dentes da madama, será a predição para o destino de Macabéa:

- Macabéa! Tenho grandes notícias para the dar! Preste atenção, minha flor, porque é da maior importância o que vou the dizer. É coisa muito séria e muito alegre: sua vida vai mudar completamente $[\ldots] \mathrm{Um}$ dinheiro grande vai the entrar pela porta adentro em horas da noite trazido por um homem estrangeiro. $|\ldots|$ Se não me engano, e nunca me engano, ele vai the dar muito amor e você, minha enjeitadinha, você vai se vestir com veludo e cetim e até casaco de pele vai ganhar! [...] Pois vai ter só para se enfeitar. Faz tempo que não boto cartas tão boas. E sou sempre sincera: por exemplo, acabei de ter a franqueza de dizer para aquela 
moça que saiu daqui que ela ia ser atropelada, ela até chorou muito, viu os olhos avermelhados dela? (HE. p. 76-77).

O desfecho, como sabemos, é que o destino de Macabéa é justamente aquele que a cartomante dissera ser o da outra cliente; a protagonista, sabemos ao fim, vai morrer sob as rodas de um mercedes amarelo. Perceba-se aqui a inversão que ocorre no nível da diegese - a morte de uma no lugar da outra, ardil narrativo, como metáfora da inversão escritural, mais séria, portanto, do que o primeiro deslocamento, ocorrida tal inversão, agora, no plano do ato de narrar, ou seja, o discurso da autoconsciência narratorial, representado literariamente pela figura enganadora da cartomante ("E sou sempre sincera”), parodia o discurso sério de Rodrigo S. M., narrador oficial desse texto. Dizer, por exemplo, como diz a cartomante, que nuncal se engana ou que nunca engana e que é sempre sincera corresponde às exigências de verossimilhança, que, afinal, é o disfarce da literatura centrada no modelo estético da tradição. Já a história, representada por Rodrigo S. M., é a história tal como vista na entrada do século XIX. quando se convencionou identificar a verdade com o fato, contrapondo-se ao reino da fícção, pois "o objetivo do historiador do século XIX era", como diz Hayden White, "expungir do seu discurso todo traço de fictício, ou simplesmente do imaginável, abster-se das técnicas do poeta e do orador e privar-se do que se consideravam os procedimentos intuitivos do criador de ficções na sua apreensão da
realidade".

Assim, enquanto a função de Rodrigo S. M. é parafrasear uma conduta, a do historiador, com os rigores da palavra verdadeira, a função da cartomante, nesse diálogo, é, por sua vez, parodiar o discurso literário que se pretende verossímil e afinado com as convenções do realismo. O realismo de Clarice Lispector, mesmo numa obra que tem o tom de denúncia crítica do real, é um realismo perpassado pela desmontagem moderna do mesmo princípio que o sustenta, pois se autoquestiona, reflete sobre as condições mesmas desse realismo. Pois, uma vez morta a protagonista, alvo da atenção do narrador-historiador, este sentencia: "Macabéa me matou". Com esse gesto dramático, ele rompe, enfim, com a ilusão de realidade aro

6 WHITE. Hayden. Trópicos do discurso. Tradução Alípio Correcia de Franca Neto. São Paulo: Edusp, 1994. (Ensaios de cultura, 6). p. 139-140). 
Diálogo de identidades discursivas em A hora da estrela

fazer romper-se a "distância estética" colocada no romance tradicional entre a instância narradora e a coisa narrada, ou, no dizer de Adorno (1983, p.269-273), entre o comentário e a ação.

\section{O resto é silêncio}

Rodrigo S. M. é vencido pela modernidade ao declarar-se aniquilado. Deixa de ser o narrador que conduz o leitor para ser tragado pelo movimento da ficção. Diz ele ao público que o escuta: "Não vos assusteis, morrer é um instante, passa logo, eu sei porque acabo de morrer com a moça. Desculpai-me esta morte. É que não pude evitá-la". Sinal máximo de rendição. De estrangulamento. Depois fíca só o silêncio. Silêncio não é fim nem morte. É vida, é reinício.

Morta Macabéa, liberta-se a literatura da dependência dos rigores da escrita da história factual, como o foi no romance do século XIX. Como que morre Rodrigo S. M., o narrador-historiador; fecha-se então o ciclo do discurso bíblico, grandiloqüente, que iniciara a narrativa: "Se um dia Deus vier à terra haverá silêncio grande" (p. 86). Relativiza-se assim a autoridade do discurso do historiador. Despedese o narrador, caindo enfim no banal mundo das coisas simples ao tempo em que - como diz Adorno (ibidem, p.273) em relação ao romance contemporâneo, chamando-o de epopéia negativa - "o indivíduo liquida a si mesmo". Rodrigo S. M., finalmente, reconhece o quão provisório é o seu saber sobre tudo que relatou, pondo $\mathrm{cm}$ xeque, nas palavras finais, a concepção da história linear, que pretensamente almejava alcançar o fim e o sucesso como valores máximos. Fica, agora, apenas a sensação da inutilidade desse percurso:

E agora - agora só me resta acender um cigarro e ir para casa. Meu Deus, só agora me lembrei que a gente morre. Mas - eu também?! Não esquecer que por enquanto é tempo de morangos (HE, p.87). 


\section{Referências Bibliográficas}

ADORNO, Theodor W. et alii. Textos escolhidos. 2. ed. São Paulo: Abril Cultural, 1983 (Os pensadores). Posição do narrador no romance contemporâneo, p. 269-273.

BAKHTIN, Mikhail. Questões de literatura e de estética: a teoria do romance. Tradução Aurora Fornoni Bernardini et alii. São Paulo: Hucitec; Fundação para o Desenvolvimento da Unesp, 1988.

CULLER, Jonathan. Teoria literária: uma introdução. Tradução Sandra Vasconcelos. São Paulo: Beca Produções Culturais Ltda..
1999.

CURTIUS, Ernest Robert. Literatura européia e Idade Média latina. 1996 (Clássicos, 2). LIMA, Luiz Costa. Terra ignota: a construção de Os sertões. Rio de Janeiro: Civilização Brasileira, 1997. História e literatura, p.213-237.

LISPECTOR, Clarice. A hora da estrela. Rio de Janeiro: Rocco, 1998. WHITE, Hayden. Trópicos do discurso. Tradução Alípio Correia de Franca Neto. São Paulo: Edusp, 1994 (Ensaios de cultura). 